\title{
Clinical Impact of RehaCom Software for Cognitive Rehabilitation of Patients with Acquired Brain Injury
}

\author{
Elízabeth Fernández MS, María Luisa Bringas PhD, Sonia Salazar, Daymí Rodríguez, María Eugenia García MS, \\ Maydané Torres MS
}

\begin{abstract}
We describe the clinical impact of the RehaCom computerized cognitive training program instituted in the International Neurological Restoration Center for rehabilitation of brain injury patients. Fifty patients admitted from 2008 through 2010 were trained over 60 sessions. Attention and memory functions were assessed with a pre- and post-treatment design, using the Mini-Mental State Examination, Wechsler Memory Scale and Trail Making Test (Parts A and B). Negative effects were assessed, including mental fatigue, headache and eye irritation. The program's clinical usefulness was confirmed, with $100 \%$ of patients showing improved performance in trained functions.
\end{abstract}

KEYWORDS Acute brain injuries; traumatic brain injury; brain injury, vascular; rehabilitation; intellectual disability; neuropsychology; Cuba

\section{INTRODUCTION}

The increasing number of people with disabilities resulting from acquired brain injury concerns specialists in many countries worldwide.[1-3]

Acquired brain injury refers to a lesion in a brain with previously normal development. Irrespective of its cause-whether traumatic brain injury (TBI), stroke, tumors, hypoxia or encephalitis-such a lesion may provoke physical and motor skill impairment and serious psychological consequences. The latter may affect cognition, impairing processes such as attention and concentration, memory, planning, calculations and language; as well as emotions and behavior.[4-6] These disorders severely limit individual autonomy for successful reintegration into family, work and social life.[7,8]

Growing interest in recovery from these sequelae has led to development of multiple therapeutic strategies for cognitive rehabilitation, that is, the remediation or alleviation of cognitive deficits resulting from neurological damage.[9] Cognitive rehabilitation is an interactive and dynamic training process involving the patient and treatment team.[10] The biological basis of its amelioration of neuropsychological sequelae resides in brain neuroplasticity.[11-14]

Rehabilitation services have expanded in Cuba with involvement of skilled personnel at all levels of the health system.[15] Several kinds of specialists participate in brain injury treatment, with neuropsychologists playing a fundamental role. Many work in provincial or national neurology hospitals or in neurology, neurosurgery and rehabilitation services of general, adult clinical-surgical and pediatric hospitals.[15] Among their clinical and scientific functions, these specialists verify presence, severity and location of brain injury; determine neuropsychological sequelae and which cognitive functions have been preserved; diagnose cognitive impairment at all ages; and recommend the most effective strategies for stimulation and rehabilitation of processes affected.[16]
The rehabilitation program at the International Neurological Restoration Center (CIREN, the Spanish acronym) in Havana implements advances in neurorehabilitation using an intensive, personalized, comprehensive and multidisciplinary approach. [17] Patients admitted to CIREN have suffered brain injuries, usually severe ones. A review of clinical histories and neuropsychological results of adult patients with nondegenerative lesions seen in CIREN from 2008 to 2010 found a $92 \%$ prevalence of cognitive dysfunction of varying severity. These patients received cognitive rehabilitation as well as therapy for motor sequelae.

Neuroscience and technological developments have enabled automation of many cognitive training procedures, making it possible to meet demand for care, improve stimulation quality, increase patient record reliability and optimize performance in impaired functions.[18-20] One recently implemented program is the RehaCom system (Schuhfried, Austria), which has shown excellent results in clinical practice with no major negative effects reported.[21]

\section{INTERVENTION}

A technology assimilation intervention using the RehaCom system was carried out at CIREN on a group of patients with cognitive disorders caused by stroke and TBI.

Objective Assess usefulness of the RehaCom system for cognitive rehabilitation of patients with acquired brain injury due to stroke and TBI.

Rationale Neuropsychological impairments caused by TBI and stroke interfere with successful social and occupational reintegration, often more so than do physical sequelae. These conditions require immediate and specialized care, since quality of life is directly related to degree of cognitive impairment and the most important concern of patients and family members is loss of autonomy. The social costs of lost productivity are particularly high when young people of working age are affected.[22]

The elevated prevalence of cognitive dysfunction associated with acquired brain injury makes cognitive rehabilitation essential. Introduction of new neuropsychological rehabilitation tools based on the latest developments in computer sciences is both necessary and scientifically challenging for health professionals, particularly neuropsychologists.

Study group Participants were 50 adult patients who met the following inclusion criteria: neurologic diagnosis of stroke or TBI, admitted to CIREN from 2008 through 2010, aged 20 to 80 years, with cognitive dysfunction per neuropsychological assessment, and seen in the Adult Static Brain Lesions Clinic. Excluded were patients with diagnosis of degenerative nervous system or psychiatric disease, aphasia, cognitive developmental delay, or who were illiterate. 
The prevalence of TBI in the study group was 58\% (29/50), followed by $42 \%$ (21/50) for stroke. Most, 68\% (34/50), were men; and $66 \%(33 / 50)$ had completed between 10 and 15 years of formal education. Sixty-eight percent (34/50) were aged 20 to 39 years. Over half the subjects in rehabilitation had been affected for one to five years.

Despite impaired attention and memory processes, overall cognitive impairment was mild with a Mini-Mental State Examination (MMSE) of 20-24 points in 66\% (33/50) and moderate (MMSE: $15-19$ points) in 34\% (17/50).

All patients had motor disorders, including hemiparesis, hemiplegia and cerebellar ataxia; 76\% (38/50) had vision problems (hemianopsia, diplopia, artificial eye); and 14\% (7/50) had diminished hearing.

Clinical usefulness of the software was assessed using the following variables:

- Flexibility: Proportion of patients included in the study who participated in therapy irrespective of sensorimotor deficits.

- Dynamics: Personalized increase in task difficulty level according to individual patient progress.

- Accessibility: Ease of use for people from countries with different languages, whether from more or less developed regions or population areas.

- Clinical validity: Fulfillment of therapeutic objectives; e.g., enables recovery of higher cognitive functions, measured by pre- and post-treatment performance on Wechsler Memory Scale and Trail Making Test, Parts A and B.

- Safety: Acceptable balance of risk to benefits. Adverse effects during program use were assessed.

- Objectivity: Results expressed in completion times and error counts.

Neuropsychological assessment methods The MMSE was used to classify patients' overall cognitive impairment as mild (20-24), moderate (15-19) or severe (0-14).[16]

Trail Making Test (Parts A and B) was used to assess focused or selective attention with visual inspection. Part $A$ evaluates simple attention by ability to detect numbers in ascending order; Part $\mathrm{B}$ evaluates executive attention by ability to simultaneously detect ascending orders of letters and numbers. Measurement is in seconds.[16]

The seven subtests of the Wechsler Memory Scale were used to assess and diagnose memory disorders in different modalities: orientation (5 points), information (6 points), mental control (9 points), digit span (17 points), associative learning (21 points), logical memory (23 points) and visual memory (15 points). The maximum crude score that can be obtained is 96 points; a correction ranging from 33 to 48 points is added for age to obtain the final score. Performance is classified using the following ranges: impaired $\leq 69$; borderline impaired 70-79; slow normal 80-89; mid normal 90-109; high normal 110-119.[16]

Cognitive rehabilitation method Patient training used RehaCom software for interactive computerized cognitive rehabilitation, a complete description of which has been published.[21] RehaCom includes activation and stimulation of several cognitive domains such as attention, memory, visual-spatial processes and execu- tive functioning. The program contains several modules with different levels of difficulty, automatically increasing task difficulty level as the subject successfully executes simpler procedures. Recording of number of errors and test completion time for all patients and a training results file enable continuity over several sessions and database storage of results. The computer gives patients appropriate instructions and feedback on performance in their own language (in our patients, Spanish, English or Portuguese). The following were the areas of training: divided attention, concentration, reaction (time), word memory, verbal memory (i.e., whole text, not just individual words), spatial memory and figure memory.[21]

Procedures and Ethics Therapists familiarized themselves with the program for two months before commencement of patient training. A neuro psychologist performed an intial evaluation during the standard assessment week required for all patients on admission to CIREN. An external evaluator, a psychologist, administered attention and memory tests before and after training, each patient serving as his or her own control.

The study protocol was approved by CIREN's ethics committee. Patients provided written informed consent before enrolling in training.

Patients received 60 training sessions over 12 weeks, divided into five 50-minute sessions per week. All sessions were held in the morning in a laboratory designed for this purpose, where up to four patients worked simultaneously under supervision by two specialists. Patients were monitored for possible negative effects during training.

Data processing Descriptive statistics were used (percentage, mean and standard deviation). To assess training effect, differences between pre- and post-training measures of attention and memory test performance were analyzed using the Student t test with statistical significance set at $p<0.05$.

\section{RESULTS}

Flexibility One hundred percent of the patients were able to enroll in treatment, irrespective of sensory and motor deficits secondary to brain injury and without requiring any special accessories.

Dynamics In $100 \%$ of cases, the program permitted personalized increases in task difficulty according to individual progress. It permitted use of a wide variety of interchangeable stimuli and objects; this versatility was conducive to keeping the patient focused on rehabilitation. Moreover, in all cases the therapist was able to monitor difficulty level and even to identify and evaluate which features of stimuli used in rehabilitation or assessment tests were most significant for the subject and whether his or her cognitive performance had improved.

Accessibility In $100 \%$ of participants, the language was successfully set to that of the patient's country of origin.

Clinical validity Ninety-seven percent of participants completed all therapy sessions. Table 1 shows pre- and post intervention results of neuropsychological tests. All cases showed reduced cognitive deficit; and all exhibited reduced completion time for both simple selective attention and executive attention, although the difference was only statistically significant for simple attention. 
Improvements in all parameters related to memory were statistically significant. Figure 1 displays the change in patient distribution across the range of Wechsler Memory Scale scores; at the conclusion of the intervention, there was a substantial increase in the proportion of patients in the higher ranges and a corresponding reduction in the range of greater memory impairment, demonstrating achievement of therapeutic objectives.

Table 1: Neuropsychological assessment scores pre- and postintervention

\begin{tabular}{|c|c|c|c|c|}
\hline \multirow{3}{*}{ Variable } & \multicolumn{4}{|c|}{$\begin{array}{c}\text { Neuropsychological } \\
\text { Assessment }\end{array}$} \\
\hline & \multicolumn{2}{|c|}{ Initial } & \multicolumn{2}{|c|}{ Final } \\
\hline & Mean & SE & Mean & SE \\
\hline Simple attention ${ }^{\mathrm{a}}(\mathrm{s})$ & 112.4 & 10.9 & $88.5^{*}$ & 9.4 \\
\hline Executive attention ${ }^{\mathrm{a}}$ (s) & 112.6 & 15.8 & 93.1 & 13.8 \\
\hline Orientation $^{b}$ (5 points) & 4.0 & 0.2 & $4.6^{*}$ & 0.1 \\
\hline Information ${ }^{b}$ (6 points) & 4.5 & 0.2 & $5.1^{*}$ & 0.1 \\
\hline Mental control $^{\mathrm{b}}(9$ points $)$ & 5.7 & 0.3 & 7.0* & 0.3 \\
\hline Digit span ${ }^{b}$ (17 points) & 7.1 & 0.3 & $8.4^{*}$ & 0.3 \\
\hline Associative learning ${ }^{b}(21$ points) & 9.5 & 0.6 & $11.2^{*}$ & 0.6 \\
\hline Logical memory ${ }^{b}(23$ points) & 5.7 & 0.5 & $8.4^{*}$ & 0.6 \\
\hline Visual memory ${ }^{\mathrm{b}}$ (15 points) & 6.3 & 0.4 & $8.0^{*}$ & 0.4 \\
\hline Overall memory ${ }^{b}$ (normal $\geq 90$ ) & 75.9 & 2.2 & $88.7^{*}$ & 2.7 \\
\hline
\end{tabular}

* $p<0.05$

SE: Standard Error

a Trail Making Test

${ }^{\mathrm{b}}$ Wechsler Memory Scale

Safety Adverse effects attributable to the therapy included mental fatigue in $14 \%(7 / 50)$ of patients during the first six sessions. Likewise, $6 \%(3 / 50)$ of patients reported headache. Symptoms resolved in all patients as they progressed with therapy and became more familiar with it. These negative effects can be considered minimal and therefore acceptable in relation to reported benefits.

Objectivity In $100 \%$ of the study sample, results were monitored quantitatively and automatically during all work sessions, with completion times and number of errors recorded individually for all computerized tasks.

\section{LESSONS LEARNED}

Progress in multimedia technology and its generalized use have led to design of applications in new areas, such as educational software for neuropsychological rehabilitation. There is consider-
Figure 1: Wechsler Memory Scale ranges obtained, pre- and post intervention

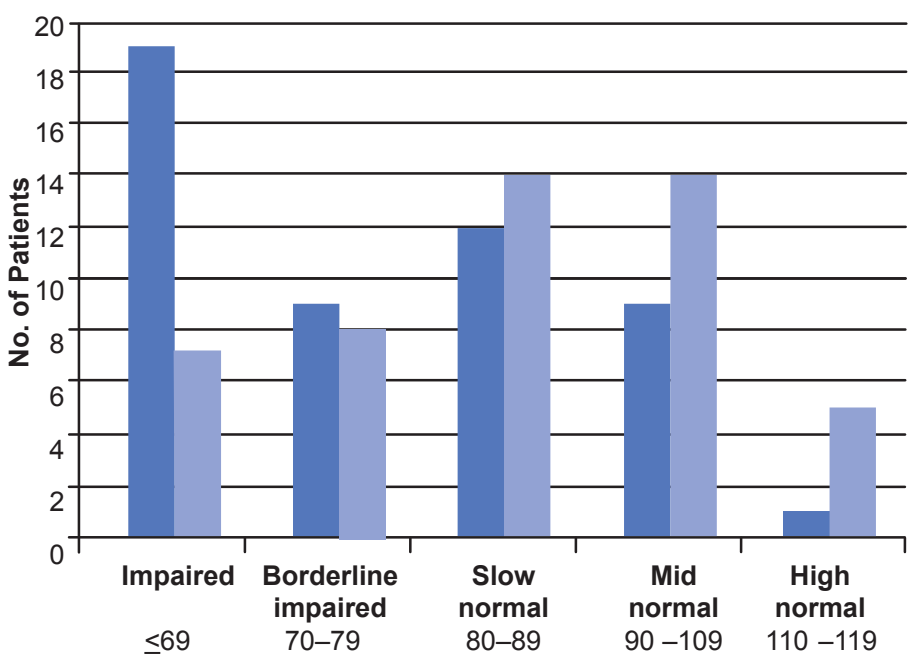

Wechsler Memory Scale Ranges

Pre-intervention Post-intervention

able evidence for the modulating effect of cognitive rehabilitation on recovery from neuropsychological impairment in patients with acquired brain injury.[23,24] These interventions increase the chances of optimal recovery. From this perspective, neuropsychology is expanding its sphere of action in rehabilitation, encompassing both assessment and treatment of sequelae.

The RehaCom program has sufficient flexibility, simplicity, accessibility, dynamics and objectivity to make a useful contribution to clinical practice. Its interactive capabilities and multimedia make it possible to treat a large number of patients and keep them motivated, irrespective of multiple motor and sensory deficits. Its use enables more precise recording of patient results and increased quality of stimulation. Our results are consistent with other reports of the program's effectiveness in recovery of attention and memory, with reliable progress and transfer effects to other functions.[23,24]

The use of RehaCom has corroborated once more that sustained stimulation is a basic principle in functional recovery after brain injury. -1 -

\section{REFERENCES}

1. Pérez Ortiz L, Rodríguez Ramos E. El examen físico del paciente con trauma craneal. Rev Méd Electrón [Internet]. 2011 Jun-Jul [cited 2011 Sept 11];33(4). Available from: http://www.revmata nzas.sld.cu/revista\%20medica/ano\%202011/ vol4\%202011/tema09.htm. Spanish.

2. Cuthbert JP, Corrigan JD, Harrison-Felix C, Coronado V, Dijkers MP, Heinemann AW, et al. Factors that predict acute hospitalization discharge disposition for adults with moderate to severe traumatic brain injury. Arch Phys Med Rehabil. 2011 May;92(5):721-30.

3. Wang Y, Alvarez G, Salinas R, Ramírez G, Catalán $\mathrm{M}$, Díaz $\mathrm{C}$. Análisis del cumplimiento de la Guía Clínica del AUGE en pacientes con accidente cerebrovascular isquémico: la utilización de tecnología sanitaria de diagnóstico para prevención secundaria en un hospital público. Rev Med Chile [Internet]. 2011 Jun [cited 2011 Aug
10];139(6):697-703. Available from: http://www .scielo.cl/pdf/rmc/v139n6/arto1.pdf. Spanish.

4. Buller PI. Diagnóstico y rehabilitación neuropsicológica. Cuad Neuropsicol. 2008;2(1):10-23. Spanish.

5. Ríos-Lago M, Muñoz-Céspedes JM, Paúl-Lapedriza N. Alteraciones de la atención tras daño cerebral traumático: evaluación y rehabilitación. Rev Neurol. 2007 Mar 1;44(5):291-7. Spanish.

6. Tárraga L, Boada M, Modinos G, Espinosa A, Diego S, Morera A. A randomised pilot study to assess the efficacy of an interactive, multimedia tool of cognitive stimulation in Alzheimer's disease. J Neurol Neurosurg Psychiatry. 2006 Oct;77(10):1116-21.

7. Odriozola F, Ibarrarán M, Gorostidi A, Murgialdai A, Marco P. Pronóstico de las secuelas tras lesión cerebral. Med Intensiva. 2009;33(4):17181. Spanish.
8. Boosman H, Visser-Meily JM, Post M, Lindeman E, Van Heugten CM. Exploring the relation between learning style and cognitive impairment in patients with acquired brain injury. Neuropsychol Rehabil. 2012 Jan;22(1):26-39.

9. Wilson BA, Gracey F, Evans JJ, Bateman A Neuropsychological rehabilitation. Theory, mod els, therapy and outcome. New York: Cambridge University Press; 2009. 380 p.

10. Fernández Guinea S. Estrategias a seguir en e diseño de los programas de rehabilitación neuropsicológica para personas con daño cerebral. Rev Neurol. 2001 Aug 16;33(4):373-7. Spanish.

11. Helmstaedter C, Loer B, Wohlfahrt R, Hammen A, Saar J, Steinhoff BJ, et al. The effects of cognitive rehabilitation on memory outcome after temporal lobe epilepsy surgery. Epilepsy Behav. 2008 Apr;12(3):402-9. 
12. Carvajal-Castrillón J, Henao EA, Uribe C, Giraldo M, Lopera F. Rehabilitación cognitiva en un caso de alteraciones neuropsicológicas y funcionales por traumatismo craneoencefálico severo 1. Rev Chilena Neuropsicol. 2009;4(1):52-63. Spanish.

13. Neil-Pirozzi TMO, Strangman GE, Goldstein $\mathrm{R}$, Katz DI, Savage CR, Kelkar R, et al. A controlled treatment study of internal memory strategies (I-MEMS) following traumatic brain injury. J Head Trauma Rehabil. 2010 JanFeb;25(1):43-51.

14. Ginarte Y. La neuroplasticidad como base biológica de la rehabilitación cognitiva. Geroinfo. 2007;2(1):1-14. Spanish.

15. Bringas ML, Fernández $Y$, García ME, Ruiz E, Casabona E, Fernández E, et al. Neuropsicología en Cuba. Rev Neuropsicología, Neurociencias y Neuropsiquiatría. 2009 Oct;9(2):53-76. Spanish.

16. Ardila A, Rosselli M. Neuropsicología Clínica. Bogotá: Editorial El Manual Moderno. S.A. de C.V; 2008. 364 p. Spanish.

17. Sentmanat A. De vuelta a la vida. Sistema de Neurorrehabilitación Multifactorial intensivo. Madrid: Editorial Sangova S.A.; 2003. Spanish.

18. Fernández-Calvo $B$, Rodríguez-Pérez $R$, Contador I, Rubio-Santorum A, Ramos F. Eficacia del entrenamiento cognitivo basado en nuevas tecnologías en pacientes con demencia tipo Alzheimer. Psicothema. 2011;23(1):44-50. Spanish.
19. Owen AM, Hampshire A, Grahn JA, Stenton R Dajani S, Burns AS, et al. Putting brain training to the test. Nature. 2010 Jun 10;465(7299):775-8.

20. Dou ZL, Man DW, Ou HN, Zheng JL, Tam SF. Computerized errorless learning-based memory rehabilitation for Chinese patients with brain injury: A preliminary quasi-experimental clinica design study. Brain Inj. 2006 Mar;20(3):219 25.

21. Schuhfried G. RehaCom Version 5. Basic Manual [Internet]. Magdegurg (DE): Hasomed; c2003. 52 p. Available from: http://www.hasomed.de/ fileadmin/user_upload/Rehacom/Manuale/ENG/ RehaComEN.pdf

22. Junqué $\mathrm{C}$. Secuelas neuropsicológicas de los traumatismos craneoencefálicos. Rev Neurol. 1999 Feb 16-28;28(4):423-9. Spanish.

23. Noreña D, Ríos-Lago M, Bombín-González । Sánchez-Cubillo I, García-Molina A, TirapuUstárroz J. Efectividad de la rehabilitación neuropsicológica en el daño cerebral adquirido (I) atención, velocidad de procesamiento, memoria y lenguaje. Rev Neurol. 2010;51(11):687-98 Spanish.

24. Noreña D, Sánchez-Cubillo I, García-Molina A Tirapu-Ustárroz J, Bombín-González I, RíosLago M. Efectividad de la rehabilitación neuropsicológica en el daño cerebral adquirido (II) funciones ejecutivas, modificación de conducta y psicoterapia, y uso de nuevas tecnologías. Rev Neurol. 2010;51(I):733-44. Spanish.

\section{THE AUTHORS}

Elízabeth Fernández Martínez (corresponding author: efernandez@neuro.ciren.cu),psychologist with a master's degree in health psychology. International Neurological Restoration Center (CIREN), Havana, Cuba.

María Luisa Bringas Vega, psychologist. CIREN, Havana, Cuba.

Sonia Salazar Santana, psychometric technician, CIREN, Havana, Cuba.

Daymí Rodríguez Pérez, psychologist, CIREN, Havana, Cuba.

María Eugenia García Navarro, psychologist with a master's degree in neurosciences, CIREN, Havana, Cuba.

Maydané Torres Aguilar, disability specialis with a master's degree in education, CIREN Havana, Cuba.

Submitted: September 17, 2011

Approved for publication: September 17, 2012 Disclosures: None 